\title{
Quality of Nursing Interventions Provided to Infants \\ Receiving Mechanical Ventilation
}

Shimaa Ramadan Ahmed Abd El- Sattar .B.SC.N

Faculty of Nursing, Tanta University

Rahma Soliman Bahgat Profssor of Pediatric Nursing

Faculty of Nursing, Tanta University

Ebtisam Mohmed El-Sayed

Assistant Professor of Pediatric Nursing , Tanta University

Ahmed AbdEl Basset, Assistant professor of Pediatric Medicine

Faculty of Medicine, Tanta University

\begin{abstract}
Mechanical ventilation is a complex supportive and life saving therapy for many children with respiratory failure. Optimal outcomes for these children are achieved through the skilled delivery of standardized nursing care include management of the airway and ventilator, physical care, emotional support, pain and anxiety control and prevention of complications. The present study aimed to assess the quality of nursing interventions provided to infants receiving mechanical ventilation. The study was conducted at Pediatric Intensive Care Unit of Tanta University Hospital. It included thirty nurses working in the previously mentioned setting and sixty infants who received mechanical ventilation. Two tools were used for data collection: a structure questionnaire sheet and an observational checklist. The results revealed that, more than half of studied nurses had fair knowledge in relation to their educational level. The majority of them had poor practice in relation to the educational level and years of experience in afternoon shift comparing with morning shift. The study recommended that, in-service training programs and workshops should be conducted for those nurses to improve their knowledge and performance about standard nursing care of mechanically ventilated infants with constructive supervision and follow up by head nurses.
\end{abstract}




\section{Introduction}

Advances in respiratory care have become an integral part in the care of critically ill patients. Support of oxygenation and/or ventilation is an integral to the practice of pediatric critical care nursing because the majority of critically ill infants and children need interventions to stabilize the pulmonary system. ${ }^{(1)}$

Mechanical ventilation is the foundation of resuscitation, intensive care medicine, and anesthesia. ${ }^{(2)}$ It is an invasive life support procedure with many effects on the cardiopulmonary system to mechanically assist or replace spontaneous breathing. ${ }^{(3,4)}$ Mechanical ventilators are devices that can create a flow of gas into and out of the lungs by the manipulation of airway pressures. The main goal of the ventilator may be achieved by improving alveolar ventilation, arterial oxygenation, increasing lung

volume and reducing work of breathing. ${ }^{(5)}$ Mechanical ventilation is indicated when the patient is unable to maintain safe levels of oxygen and carbon dioxide through spontaneous breathing. ${ }^{(3)}$ It is mainly used for patients with acute respiratory failure. ${ }^{(6)}$ Respiratory failure is a sudden and life threatening deterioration of function of the lung, and inability to maintain normal arterial blood gases. ${ }^{(7-9)}$
The number of children who are suffering from respiratory failure increases annually all over the world. It is estimated that the number of children who are suffering from respiratory failure is about 1.5 million children. In Egypt, the annual statistical report of the Ministry of Health and Population in 2004 showed that, the mortality number of infants from respiratory distress was 11.656 from 1.849.638 live births. Meanwhile, the mortality number of children who are five years or less is 2708 child. $^{(1)}$

There are 79,400 hospitalizations in the United States each year for neonates undergoing mechanical ventilation, 8,500 of whom die. Importantly, almost $40 \%$ of deaths occur in cases that never receive care at higher level centers. ${ }^{(10)}$

Mechanical ventilation can be noninvasive, involving various types of face masks, or invasive, involving endotracheal intubation. Decision to initiate mechanical ventilation should be based on clinical judgment that considers the entire clinical situation and should not be delayed until the patient is in extremis. ${ }^{(11)}$ Traditionally mechanical ventilation divided into negative-pressure ventilation, where air is essentially sucked into the lungs, or positive pressure ventilation, where air (or 
another gas mix) is pushed into the trachea. ${ }^{(4)}$

Mechanical ventilation is often a lifesaving intervention, but carries many potential complications including pneumothorax, airway injury, alveolar damage, and ventilator-associated pneumonia. ${ }^{(12)}$ Endotracheal suction is one of the most common procedures carried out in an intensive care unite. Suctioning techniques are necessary nursing care used to clear the airway of thick secretions. ${ }^{(13)}$

Quality of care focused on the system of care. It is concerned with improving the processes, so that everyone's performance improves. Improvement usually requires removing the barriers in the way of the providers who already possess the motivation in order to established standard. $^{(14)}$

Nurses are constantly present at the patient's bedside, so they are the primary healthcare for monitoring the patient's respiratory status. They also responsible for notifying the respiratory therapist when mechanical problems occur with the ventilator, and when there are new physician orders that call for changes in the settings or the alarm parameters. ${ }^{(7,15)}$ The nurse is responsible for documenting frequent respiratory assessments. This usually means documenting ventilator setting and spontaneous respiratory parameters every hour, with a full respiratory assessment, including lung sounds, at least every four hours. The nurse also performs suctioning and provides oral and site care around the artificial airway. There is often a great deal of teaching and reassuring that must be done, both for the patient and their family. ${ }^{(16)}$

\section{Aim of the study:}

This study aimed to assess the quality of nursing interventions provided to infants receiving mechanical ventilation.

\section{Subject \& Methods:}

\section{Research design:-}

A descriptive design was used in this study.

\section{Setting:-}

This study was conducted at Pediatric Intensive Care Unit of Tanta University Hospital. It contained one large room with 6 pediatric beds, 6 ventilators and 2 continuous positive airway pressure devices.

\section{Subjects:-}

All available nurses working in the previously mentioned setting who are caring for mechanically ventilated infant regardless of their years of experience, level of education and their ages were included in this study. The total number of 
thirty nurses were classified as follows (12 nurses graduated from faculty of nursing, 5 nurses graduated from technical institute of nursing and 13 nurses with secondary school nursing diploma).

60 infants who received mechanical ventilation are included in this study according to the following criteria:

Their age : from one month to 12 months

Both sexes, Acute stage of respiratory disorder, Free from any chronic disease

\section{Tools of the study:-}

Two tools were used to collect the required data in this study. They were developed based on the recent literature.

Tool I: "A Structure Questionnaire Sheet". It was constructed by the researcher to assess nurses' knowledge about mechanical ventilation. It consisted of two parts:

Part (1):- Biosocial data: It was developed to assess a- nurses' sociodemographic data such as (age, level of education, years of experience and previous training). b- infant sociodemographic data such as (age, sex, date of admission, date of applying mechanical ventilation, and history of medical diagnosis).

Part (2):- Nurses' Knowledge about mechanical ventilation. It included:definition, purpose, indications, types, modes, parameters, complications, criteria used for initiation of mechanical ventilation and nursing management of infants receiving mechanical ventilation such as: (care for the tube, chest physiotherapy, suction, hygienic care "eye, oral, skin care", infection control strategies and psychological support).

The questionnaire sheet contained closed ended questions and the nurses were asked to respond to these ones with only one correct response for each; the nurses who responded " correct answer" (one) was given and the nurses who responded "incorrect answer" or "did not give any answer" (zero) was given. The "total knowledge score" was $\mathbf{5 4}$ where it comes from multiplying total number of questions (54) in the correct response score (1), and then the result is divided by 100 to be converted into percentage.

Grading of nurses' answers to questions and checklist were converted as follows: Total knowledge score from 50$\downarrow 60 \%$ was graded (poor), total knowledge score from $60-\downarrow 70 \%$ was graded (fair) and total knowledge score from $70-100 \%$ was graded (good).

\section{Tool II: "An Observational Checklist":}

It was developed by the researcher to assess the quality of nursing interventions related to the actual nursing care provided 
to infants receiving mechanical ventilation.

It comprised $\mathbf{5}$ main items:

\section{1-Provide care for the tube:}

- All tubes must be secured to decrease tube movement and accidental extubation.

- Inspect the skin, nose, and mouth for tissue breakdown.

- Change tracheostomy tape or endotracheal tube tape as needed.

- Move the oral endotracheal tube to the opposite side of the mouth every 24 hours.

- Frequently assess the tube's position

\section{2-Make Suction:}

- When secretions are present.

- Prepare all needed equipment before the procedure.

- Use the appropriate catheter size.

- Duration of the suctioning.

- Apply pre-oxygenation be considered for 30-60 seconds prior.

- Physical assessment such as rate and depth of respiration, nature of breathing sound.

3- Provide general hygienic care: including: Eye care, Mouth care and Skin care.

\section{a) Eye care:}

- Instillation of ophthalmic ointment or drops decreases corneal drying.

- The infant's eye should be swapped with normal saline regularly.
- Apply antibiotic drops or ointment to the eye as ordered.

- The eyelids of the infant should be closed to prevent corneal ulceration.

\section{b) Mouth care:}

- Mouth care at least once per shift by using oral swab.

- lubricate lips with water-soluble ointment to prevent drying of lips.

-Reposition or rotate the endotracheal tube from one corner of the mouth to the opposite side every 24 hours.

\section{c) Skin care:}

- Bath the infant daily.

- Change position every 2 hours.

- keep infants clothes clean, dry and keep bed free from any objects.

- Lubricate the back and bony prominence and frequent massage for the back should be done.

\section{4- Follow infection control strategies:}

- Washing hands before handling the infant, before and after any procedure.

- Use isolation technique of infant who has any infectious disease away from other infants.

- Avoid exposing the infant to persons with upper respiratory tract infection.

- Remove or empty water that accumulates in the ventilator tubing. 
-Methods and schedules of cleaning and disinfection of ventilator circuits should be learned and applied.

\section{5-Psychological support:}

- Provide an emotional support to the infant by applying distraction techniques as: allowing the infant to listen to stories \& quiet music, providing back rub \& gentle massage and offering attractive $\&$ safe toys for conscious infants.

Different nursing activities related to each item were listed. A scoring system was used to check each activity whether it was adequately done, inadequately done or not done. Scoring of (two points) was given to adequate nursing activity; (one point) was given to inadequate nursing activity and (zero) for not done nursing activity with a total score of (334) where it comes from accumulating the number of steps of all nursing care procedures (167) multiplied in adequate nursing activity score (2) then the result is divided by 100 to be converted into percentage.

The total score of each item was (34 points for chest physiotherapy, 40 points for care of the endotracheal tube, 36 points for nasopharyngeal and oropharyngeal Suction, 38 points for endotracheal Suction, 98 points for general hygienic care (28 points for eye care, 38 points for mouth care, 32 points for skin care), 62 points for infection control strategies ( 24 points for application of standard precautions and transmission based precautions, 10 points for care of ventilator, 28 points for central venous catheter care), and 26 points for Psychological support.

Grading of checklist nursing practice were converted as follows: from $60-\downarrow 65 \%$ was graded "poor", $65-\downarrow 70 \%$ was graded "fair", 70-100 \% was graded "good".

\section{Method}

- An official permission was obtained from the directors of hospital of the selected setting (PICU at Tanta University Hospital).

- Meeting with nurses before starting data collection procedure was done to establish a good relationship, check the availability of conducting the research, and to explain the purpose of the study.

- An oral consent was obtained from the nurses to participate in the study after explanation of the purpose and importance of the study.

- Study tools were structured and developed based on review of the related literature.

\section{- Ethical considerations:-}

Nurses were informed of the privacy of information obtained from them, nature of the study, their right to withdraw from the study at any time and the confidentiality of their names. 
- The pilot study: Pre-test of the used tools was carried out at the above mentioned setting before starting the data collection .It was done on $10 \%$ of the study sample to assess clarity, reliability, applicability of the study tools, the time needed to fill each tool, and to identify obstacles that might be faced during data collection. The sample which was included in the pilot study was a part of the studied sample.

- A structure questionnaire sheet was developed to assess the nurses' basic information and knowledge related to mechanical ventilation.

-The questionnaire sheet was distributed on nurses; the content of the sheet was explained to all of them and filled individually. The nurses were reassured that all information will be confidential and used only for the purpose of the study and nurses were asked to respond in the presence of the researcher.

- The time required for answering the questionnaire sheet was about one hour.

- Each nurse was observed twice in the morning and afternoon shifts by the researcher to assess her care provided to the infant receiving mechanical ventilation by using observational check list.

- The time required to the researcher for checking the observational checklist for each nurse was about 2 intermittent hours.
-Data were collected over a period of 4 months from October 2011 to January 2012.

\section{Statistical analysis:}

The collected data were organized, tabulated and statistically analyzed using SPSS statistical package version 19. Numerical variables were presented as range, mean and standard deviation for categorical variables, the number and percent distribution was calculated. Statistical analysis for factors affecting the total score of knowledge and practice was done using Mann-Whitney test as the small sample size for each studied categories was small and did not guarantee normal distribution to use the student ttest. Comparison of mean values for chest physiotherapy, hygiene and infection control was performed using paired t-test as the total cases were treated as one group. For comparisons of observations of items related to knowledge or practice between morning and afternoon shifts, Wilocxon signed rank test. The level of significance was adopted at $\mathrm{p}<0.05$.

\section{Limitations of the study:}

- Lack of interest and cooperation of studied nurses.

- Many of nurses were too overloaded with their work particularly in afternoon shift. 
- There were many interruptions during answering the questionnaires.

- Small sample size to make generalization.

\section{Results:}

Table (1) presents the percentage distribution of the studied nurses regarding biosocial-demographic characteristics. It was revealed that, more than half of nurses' ages $(56.7 \%)$ were more than 30 years while $40 \%$ of them were between the age of 20 and 30 years and the rest of them $(3.3 \%)$ were less than 20 years. In relation to nurses' educational level, $43.3 \%$ of studied nurses had secondary school nursing diploma while more than one third of them (40\%) had university education and the rest of them (16.7\%) had technical nursing institute. Regarding years of experience in pediatric intensive care unit, it was clear that the majority of nurses $(83.3 \%)$ had more than 3 years of experience. In relation to nurses' previous training on care of mechanically ventilated infants, it was found that the majority of them $(93.3 \%)$ had no previous training.

Table (2) shows mean and standard deviation of total score percentage of different items of knowledge among studied nurses. It was observed that the mean total knowledge score of nurses regarding infection control was
(86.67 \pm 26.04$)$ and ranged between zero and $100 \%$. Also, the mean total knowledge score of nurses regarding endotracheal tube care was $(71.33 \pm 20.13)$ and ranged between $40 \%$ and $100 \%$. However, the mean total knowledge score of nurses regarding mechanical ventilation and suctioning procedure was $(36.67 \pm 23.73)$ and ranged between zero and $66.67 \%$ for each.

Table (3) illustrates percentage distribution of studied nurses according to total score of nurses' knowledge. Results revealed that about one third of nurses $(30 \%)$ had poor total knowledge score (50$\downarrow 60 \%)$. However, more than half of studied nurses $(56.7 \%)$ had fair total knowledge score $(60-\downarrow 70 \%)$ and the rest of them $(13.3 \%)$ had good total knowledge score $(70-100 \%)$.

Table (4) illustrates percentage distribution of studied nurses of total practice score related to different items of practice. In relation to general hygienic care, it was found that the total practice score percentage of general hygienic care in the morning shift ranged between $66.3 \%$ and $82.6 \%$ while, in the afternoon shift, the total practice score percentage ranged between $62.2 \%$ and $84.7 \%$. Also, results revealed that, the mean total practice score percentage of general hygienic care in 
morning shift $(75.23 \pm 5.57)$ was more than that in the afternoon shift $(72.11 \pm 7.13)$. However, in relation to endotracheal tube care, it was found that the total practice score percentage of endotracheal tube care in the morning shift ranged between $47.5 \%$ and $60 \%$ while in the afternoon shift, the total practice score percentage ranged between $42.5 \%$ and $62.5 \%$. Also, results revealed that the mean total practice score percentage of endotracheal tube care in morning shift $(53.92 \pm 3.92)$ was more than that in the afternoon shift $(51.42 \pm 5.11)$.

There was a statistical significant difference between total practice scores of nurses in relation to "endotracheal tube care","suctioning procedure", "endotracheal suctioning" and "eye care" in morning and afternoon shifts $(\mathrm{P}=$ 0.016, 0.011, 0.003, 0.001 respectively) .

Table (5) illustrates percentage distribution of studied nurses according to total score of nurses' practice. In morning shift, it was found that the majority of studied nurses (90\%) had poor total practice score where it ranged from 60$\downarrow 65 \%$. Low percentage of nurses $(10 \%)$ had fair total practice score where it ranged from $65-\downarrow 70 \%$ and no one of them had good practice score where it ranged from $70-100 \%$. In afternoon shift, it was found that more than three quarters of studied nurses $(76.7 \%)$ had poor total practice score. However, low percentage of nurses $(16.7 \%)$ had fair total practice score and the rest of them (6.7\%) had good total practice score.

Table (6) illustrates correlation between total knowledge and practice scores. It was found that there was no statistical significant difference between total nurses' knowledge score and total nurses' practice score in morning shift $(\mathrm{P}=0.162$ and $\mathrm{r}=$ 0.262) . Also, results revealed that there was a statistical significant difference with positive correlation between total nurses' knowledge score and total nurses' practice score in afternoon shift $(\mathrm{P}=0.044$ and $\mathrm{r}=$ 0.370). It was found that there was a statistical significant difference with weak positive correlation between total practice scores at morning and afternoon shift $(\mathrm{P}=$ $\begin{array}{llll}0.015 \text { and } & \mathrm{r} & = & 0.439)\end{array}$ 
Table (1): Percentage distribution of the studied nurses regarding

Biosocial-demographic characteristics

\begin{tabular}{|c|c|c|}
\hline Biosocial-demographic characteristics & \multicolumn{2}{|c|}{$(\mathbf{n}=\mathbf{3 0})$} \\
\hline Age in years: & No & $\%$ \\
Less than 20 years & 1 & 3.3 \\
Mo-30 & 12 & 40.0 \\
\cline { 2 - 3 } More than 30 & 17 & 56.7 \\
\hline Educational level: & 13 & 43.3 \\
Secondary school nursing diploma & 5 & 16.7 \\
Technical nursing institute & 12 & 40 \\
Bachelor degree & 2 & 6.7 \\
Years of experience in PICU: & 3 & 10.0 \\
$<1$ & 25 & 83.3 \\
\hline 1-3 & & \\
$>3$ & 2 & 6.7 \\
Previous training on care of & 28 & 93.3 \\
mechanically ventilated infants: & Yes & \\
No & & \\
\hline
\end{tabular}

Table (2) Mean and standard deviation of total score percentage of different items of knowledge among studied nurses

\begin{tabular}{|l|c|c|c|}
\hline \multicolumn{1}{|c|}{ Items of knowledge } & Range & Mean & SD \\
\hline $\begin{array}{l}\text { Mechanical } \\
\text { ventilation }\end{array}$ & $0-66.67$ & 36.67 & 23.73 \\
\hline $\begin{array}{l}\text { Endotracheal tube } \\
\text { care }\end{array}$ & $40-100$ & 71.33 & 20.13 \\
\hline $\begin{array}{l}\text { Suctionning } \\
\text { procedure }\end{array}$ & $0-66.67$ & 36.67 & 14.66 \\
\hline Chest physiotherapy & $\mathbf{0 - 1 0 0}$ & $\mathbf{5 5 . 0 0}$ & $\mathbf{3 5 . 6 0}$ \\
\hline General hygiene & $\mathbf{2 5 - 8 7 . 5}$ & $\mathbf{6 3 . 3 3}$ & $\mathbf{1 4 . 6 6}$ \\
\hline Infection control & $\mathbf{0 - 1 0 0}$ & $\mathbf{8 6 . 6 7}$ & $\mathbf{2 6 . 0 4}$ \\
\hline
\end{tabular}

Table (3): Percentage distribution of studied nurses according to total score of nurses' knowledge

\begin{tabular}{|c|c|c|}
\hline \multirow{2}{*}{ Total knowledge score percentage } & \multicolumn{2}{|c|}{$(\mathbf{n}=\mathbf{3 0})$} \\
\cline { 2 - 3 } & No. & $\%$ \\
\hline (Poor) 50- $\downarrow 60$ & 9 & 30.0 \\
\hline (Fair) 60- $\downarrow 70$ & 17 & 56.7 \\
\hline (Good) 70- 100 & 4 & 13.3 \\
\hline
\end{tabular}


Table (4): Percentage distribution of studied nurses of total practice score related to different items of practice

\begin{tabular}{|c|c|c|c|c|}
\hline $\begin{array}{l}\text { Total practice score } \\
\text { percentage related to: }\end{array}$ & $\begin{array}{c}\text { Morning } \\
\text { shift } \\
(\mathbf{n}=\mathbf{3 0})\end{array}$ & $\begin{array}{l}\text { Afternoon shift } \\
\qquad(\mathbf{n}=\mathbf{3 0})\end{array}$ & $\mathbf{T}$ & $\mathbf{P}$ \\
\hline Endotracheal tube care: & & & 2.567 & $0.016 *$ \\
\hline Range & 47.5-60.0 & 42.5-62.5 & & \\
\hline Mean & 53.92 & 51.42 & & \\
\hline SD & 3.92 & 5.11 & & \\
\hline Suctioning procedure: & & & 2.708 & 0.011* \\
\hline Range & 56.8-78.4 & 54.0-78.4 & & \\
\hline Mean & 68.51 & 65.99 & & \\
\hline SD & 6.04 & 5.999 & & \\
\hline $\begin{array}{l}\text { Nasopharyngeal and } \\
\text { oropharyngeal } \\
\text { Suction: }\end{array}$ & & & 1.786 & 0.085 \\
\hline Range & $55.56-80.56$ & $50.0-83.3$ & & \\
\hline Mean & 67.96 & 65.28 & & \\
\hline SD & 6.83 & 7.61 & & \\
\hline Endotracheal suctioning: & & & 3.203 & 0.003* \\
\hline Range & 55.3-78.9 & 55.3-76.3 & & \\
\hline Mean & 69.03 & 66.67 & & \\
\hline SD & 6.62 & 6.12 & & \\
\hline General Hygienic care : & & & $\mathbf{0 . 8 7 2}$ & 0.412 \\
\hline Range & 66.3-82.6 & 62.2-84.7 & & \\
\hline Mean & 75.23 & 72.11 & & \\
\hline SD & 5.57 & 7.13 & & \\
\hline Eye care: & & & 3.947 & 0.001* \\
\hline Range & 82.1-100 & 67.9-96.4 & & \\
\hline Mean & 90.95 & 85.12 & & \\
\hline SD & 5.03 & 8.44 & & \\
\hline Mouth care: & & & 1.349 & 0.188 \\
\hline Range & $57.9-92.1$ & 47.4-92.1 & & \\
\hline Mean & 75.09 & 75.54 & & \\
\hline SD & 10.13 & 11.01 & & \\
\hline Skin care: & & & 0.116 & 0.911 \\
\hline Range & 59.4-87.5 & 53.1-87.5 & & \\
\hline Mean & 67.01 & 66.25 & & \\
\hline SD & 7.67 & 10.04 & & \\
\hline Chest physiotherapy: & & & 0.215 & 0.803 \\
\hline
\end{tabular}




\begin{tabular}{|c|c|c|c|c|}
\hline Range & 44.1-85.3 & $17.7-85.3$ & & \\
\hline Mean & 64.51 & 63.92 & & \\
\hline SD & 12.36 & 13.44 & & \\
\hline Percussion: & & & 0.230 & 0.819 \\
\hline Range & 50.0-88.5 & $0-88.5$ & & \\
\hline Mean & 72.05 & 71.25 & & \\
\hline SD & 9.99 & 16.18 & & \\
\hline Vibration: & & & 0.000 & 1.000 \\
\hline Range & $0-60$ & $0-60$ & & \\
\hline Mean & 32.00 & 32.00 & & \\
\hline SD & 28.70 & 28.70 & & \\
\hline Infection control: & & & 0.440 & 0.665 \\
\hline Range & 45.3-73.4 & 45.3-71.9 & & \\
\hline Mean & 62.50 & 61.46 & & \\
\hline SD & 6.46 & 6.56 & & \\
\hline $\begin{array}{c}\text { Standard and } \\
\text { transmission based } \\
\text { precautions: } \\
\text { Range } \\
\text { Mean } \\
\text { SD }\end{array}$ & $\begin{array}{c}29.2-54.2 \\
45.42 \\
6.03\end{array}$ & $\begin{array}{c}37.5-50.0 \\
45.56 \\
4.67\end{array}$ & 0.133 & 0.895 \\
\hline Care of ventilator: & & & 1.613 & 0.118 \\
\hline Range & $50-80$ & $50-80$ & & \\
\hline Mean & 73.3 & 69.67 & & \\
\hline SD & 7.58 & 8.90 & & \\
\hline $\begin{array}{l}\text { Central venous catheter } \\
\text { care: } \\
\qquad \begin{array}{l}\text { Range } \\
\text { Mean } \\
\text { SD }\end{array}\end{array}$ & $\begin{array}{c}57.1-92.9 \\
77.47 \\
11.55\end{array}$ & $\begin{array}{c}50.0-92.9 \\
77.53 \\
12.35\end{array}$ & 0.052 & 0.959 \\
\hline $\begin{array}{c}\text { Psychological care : } \\
\text { Range } \\
\text { Mean } \\
\text { SD }\end{array}$ & $\begin{array}{c}26.9-73.1 \\
59.36 \\
11.85\end{array}$ & $\begin{array}{c}\text { 34.6-88.5 } \\
62.56 \\
13.88\end{array}$ & 1.214 & 0.235 \\
\hline
\end{tabular}

* Level of significance $p<0.05$ 
Table (5): Percentage distribution of studied nurses according to total score of nurses' practice

\begin{tabular}{|c|c|c|c|c|}
\hline \multirow{2}{*}{ Total practice score percentage } & \multicolumn{2}{|c|}{$\begin{array}{c}\text { Morning shift } \\
(\mathrm{n}=30)\end{array}$} & \multicolumn{2}{c|}{$\begin{array}{c}\text { Afternoon shift } \\
(\mathrm{n}=30)\end{array}$} \\
\cline { 2 - 5 } & $\mathbf{N}$ & $\%$ & $\mathbf{N}$ & $\%$ \\
\hline (Poor) 60- $\downarrow 65$ & 27 & 90.0 & 23 & 76.7 \\
\hline (Fair) 65- $\downarrow 70$ & 3 & 10.0 & 5 & 16.7 \\
\hline (Good) 70-100 & 0 & 0.0 & 2 & 6.7 \\
\hline
\end{tabular}

Table (6): Correlation between total knowledge and practice scores

\begin{tabular}{|c|c|c|}
\hline \multirow{2}{*}{ Total practice score } & \multicolumn{2}{|c|}{ Total knowledge score } \\
\cline { 2 - 3 } & $\mathrm{R}$ & $\mathrm{P}$ \\
\hline Morning shift & 0.262 & 0.162 \\
\hline Afternoon shift & 0.370 & $0.044^{*}$ \\
\hline
\end{tabular}

Correlation between practice at morning and afternoon shift: $\mathrm{r}=0.439, \mathrm{P}=0.015$ 
Discussion:

Critically ill infants in most modern PICU require a period of mechanical ventilation. Mechanical ventilation is an important supportive mode in the care of acutely and critically ill infants in general. ${ }^{(17-19)}$ Nursing care is one of the essential components of quality of care given to the infants in PICU. ${ }^{(20)}$ Therefore, pediatric nurse must have keen observation skills, highly trained and qualified especially when caring for children who are critically ill. Nurses should also be educated in the art of recognizing any changes in children behavior, interpreting the observation of other and timing intervention appropriately. ${ }^{(21)}$ This study focused on the assessment of nurses' knowledge about mechanical ventilation and the quality of nursing interventions related to the actual nursing care provided to infants receiving mechanical ventilation which comprised 5 main items "providing care for the tube, making suction and chest physiotherapy, providing general hygienic care, following infection control strategies and psychological support".

The present study revealed that more than half of nurses' ages were more than 30 years. $40 \%$ of nurses had university education. It is considered a large percentage. So, they were able to carry out their responsibilities, had a heightened awareness of resource allocation, working up on evidence-based practice and providing advanced quality of care.

Although the majority of nurses had more than three years of experience in PICU, only few of them had previous training in mechanical ventilation. This rendered them inexperienced in pediatric critical care practice. Meanwhile, it is stated that, there is a clear relationship between trained intensive care staff and quality of patient management ${ }^{(22)}$. Also, it is indicated that, the agency of Health Care Research Quality identified that in order to achieve quality of care; nurses should keep learning and conducting research rather than being stagnated in their educational background. $^{(23)}$ 
Regarding nurses' knowledge in relation to mechanical ventilation, the present study indicated that, the mean total knowledge score of nurses regarding to infection control was the highest one. While, the mean total knowledge score of nurses regarding to mechanical ventilation and suctioning procedure were the least. This may be attributed to lack of their basic knowledge and education programs regarding to mechanical ventilation and ideal care provided to mechanically ventilated infants. These findings contradicted with Carson (2000) who stated that about three quarters of nurses had correct knowledge mechanical ventilation. This could be related to the difference in educational preparation, continuous renewal of their license to practice nursing, and their continuous exposure to results of most recent researches related to management of patient on mechanical ventilation. (24) Meanwhile, these findings were consistent with Mohumed (2005) who mentioned that there was a gap between the rapid development in scientific information and slow development of knowledge of health care providers. ${ }^{(25)}$
Regarding chest physiotherapy which is composed of two basic procedures “percussion and vibration". It was observed that some nurses obtained zero the total practice score in relation to percussion and vibration procedures. This could be related to those nurses thought that chest physiotherapy was composed of percussion or vibration only, so they provided one of the two procedures and not both procedures. Also may be due to unavailability of training programs regarding to the ideal chest physiotherapy procedure.

Concerning general hygienic care, the results of the present study illustrated that general hygienic care was adequately done by about three quarters of the study nurses. This finding was consistent with study demonstrated by Zahran (1991) who observed that the general care to the eye, ear, nose, mouth and skin of the infant was adequately done by about three quarters of nurses in NICU of Tanta University Hospital. $^{(26)}$

Concerning following of infection control strategies and specifically universal and transmission based precautions for infection 
control; it was revealed that these precautions were adequately done by only less than half of nurses. These findings of the present study may be due to insufficient supplies as masks and gowns in PICU and lack of supervision and guidance by head nurses of the unit to nurses to strictly apply infection control strategies. Also, this could owe to lack of in-service training programs related to infection control strategies.

Psychological and emotional support is very important especially in Pediatric Intensive Care Unit during stressful situations. The results of the present work found that more than one third of the study nurses neglected or did not offer emotional care to mechanically ventilated infants. This may be attributed to increased and continuous workload that negatively affects the emotional status of nurses and make thepsychologically upset as the majority of them spent long years of work at PICU without psychological or financial support, so, they will not be able to give psychological support adequately to the infants in Pediatric Intensive Care Unit. Also, lack of time of the nursing staff and overlapping of nursing activities in intensive care unit, would make them focus mainly on major patient issues and would not be able to attend to minor issues as emotional support. Furthermore, the majority of infants were sedated most of the time to prevent fighting the ventilator.

This finding was consistent with the finding of Martensson et al (2004) who stated that the majority of nurses in intensive care unit neglect the patient's verbal and non-verbal communication, so the critically ill patient may experience feeling of anger, sadness, negative emotion and depression. It was stated that the role of the critical care nurse is to consider the patient's verbal and nonverbal communication ability. It is necessary for critical care nurse to help the patient to feel trust and be secure when receiving mechanical ventilation. ${ }^{(27)}$

Although more than half of studied nurses had fair total knowledge score, the majority of studied nurses had poor total practice score. This finding means that the nurses did not apply their knowledge in providing adequate nursing care to critically ill infants. These findings may be attributed to that all 
nurses follow the hospital policy in providing nursing care to mechanically ventilated infants and not to follow the standardized nursing care plan. Also, the newly recruited nurses ask the old nurse in the unit when they cannot perform any procedure instead of returning to the ideal nursing care, or may be due to lack of resources, equipments and supplies needed to provide standardized nursing care.

As regards of nursing performance, the present study revealed that the nursing care provided to infants receiving mechanical ventilation was poor and below the accepted level of what should have been done. This may be due to lack of motivation, hospital facilities, resources and lack of training courses that enable nurses to perform standardized nursing care. It was indicated that the agency of Health Care Research Quality identified that in order to achieve quality of care; nurses should keep learning, training and conducting research rather than being stagnated in their educational background ${ }^{(23)}$.

\section{Conclusion}

Based up on the results of this study, it could be concluded that nurses' knowledge and practice were inadequate to provide ideal care for mechanically ventilated infants. It was found that more than half of the studied nurses had fair knowledge in relation to their educational level and the majority of them had poor practice in relation to the their educational level and years of experience. This may be attributed to lack of supervision, and lack of motivation, resources and facilities that affect nurses' knowledge and performance.

\section{Recommendations}

Based on the findings of the present study, the following can be recommended:

- In-service training programs and workshops should be conducted periodically and regularly for nurses working in Pediatric Intensive Care Unit to improve the nurses' knowledge and performance about nursing care of mechanically ventilated infants.

- Protocol of care should be started on the admission of the infant to the unit.

- Newly recruited nurses in Pediatric Intensive Care Unit are better exposed to a sort of orientation period. During 
this period new nurses have to:

- Know about their expected roles.

- Learn about the common infant's problems and needs.

- Complement for any deficiencies in basic knowledge and skills.

- Provision of handouts of up- to- date guidelines regarding standardized nursing care of mechanically ventilated infants.

- Standardized nursing care for mechanically ventilated infants should be prepared by professional specialized adept nursing staff and kept in the unit.

\section{References}

1. Hanaa A. Quality of Nursing Interventions While Managing Children Receiving Mechanical Ventilation, Unpublished Master Thesis in Faculty of Nursing. Menouphiya University 2008; 1-4

2. Anna U, Jolanta S, Ivelisse G. Mechanical Ventilation , $3^{\text {rd }}$ ed, New York: Raven Press Co, 2010; 11-12

3. John P, Eric C, Ann R. Manual of Neonatal Care, $6^{\text {th }}$ ed, Philadelphia: Lippincott Co, 2004; 331

4. Genel L. Historical Perspective on the
Development of Mechanical Ventilation, $2^{\text {nd }}$ ed, New York: McGraw-Hill Co, 2006; 978

5. Marvin K. Mechanical ventilation of infants, Journal of American Science 2011; 7(12): 531-541

6. Witta K. New techniques for weaning difficult patient from mechanical ventilation. Clinical issue \& critical care nursing Journal, 1995; 1(2): 260.

7. Gehan A. Assessment of Nurses Knowledge and Performance in Relation to Weaning and Extubation of Patient with Mechanical Ventilation, Unpublished Master Thesis in Faculty of Nursing. Tanta University 2005; 1-2

8. Clochesy J, Breu C, Cardin S, Whillaker A , Rudy E. Critical Care Nursing, $2^{\text {nd }}$ ed, Philadelphia: WB Saunders Co, 1996; 63047

9. Smeltzer S, Bare B. Text Book of Medical Surgical Nursing, $9^{\text {th }}$ ed, Philadelphia: JB Lippincott Co, 2000; 466-467.

10. Angus D, Griffin M, Clermont G, Clark R. Epidemiology of neonatal respiratory failure in the USA: projections from 
California and New York. Am Journal

Respir Crit Care Med 2001; 164(7):11541160

11. Merck S, Dohme C. Overview of mechanical ventilation: Respiratory failure and mechanical ventilation, 2009- 2010; availableat http://www.merckmanuals.com

12. Tanıl K, Aslı K, Zahide Y, Emel D , Erdal E. Mechanical ventilation in children, Turkish Journal of Pediatrics 2006;48(4):323-327

13. Akgul S and Akyoluc N. Effect of normal saline on endotracheal suctioning, Journal clinical nurse, 2004; 11(6): 826-30

14. Institue of Medicine. Committee on quality health care in America crossing the quality chasm: A new health system For the $21 \mathrm{St}$ Centuries Washing DC: The National Academies Press 2001

15. Smeltzer S, Bare B. Text Book of Medical Surgical Nursing, $7^{\text {th }}$ ed., Philadelphia: JB Lippincott Co 2004; 200-222.

16. Walls R, Murphy M, Luten R. Manual of Emergency Airway Management, $3^{\text {rd }}$ ed, Philadelphia: Lippincott Williams and Wilkins Co, 2008; 552-565
17. Palmeri J. Developing a comprehensive preoperative nursing documentation form, AORN J, 2005; 44(18):77.

18. Ingersoll G. Measurement in mechanical ventilation weaning research, The Online $\mathrm{J}$ Known Synthesis Nurs, 1995; 2(12), 51.

19. Chase S. The research basis for weaning from mechanical ventilation, The Online J Know Synthesis Nurs, 1994; 1(7) 1-10.

20. Meade M, Guyatt G,Cook D. Weaning from mechanical ventilation: The evidence from clinical research, Respir Care J, 2001; 46(12): 1408-15.

21. Chinn P and Leitch C. Child Health Maintenance, A guide to Clinical Assessment, 6th ed., London, C.V. Mosby Co., 2000; 28-32.

22. Wong D , Hockenberry M. Wong's Nursing Care of Infants, $7^{\text {th }}$ ed, London, Mosby Co., 2003.

23. Backmann U, Gillies D. Factors associated with re-intubation in intensive care: An analysis of causes and outcomes, Chest $\mathrm{J}$, 2001; 120(2): 538-42.

24. Carson S, Ely E, Govert J, Garrett J, Hall J. Effectiveness of medical residents, Education in mechanical ventilation, 


\section{Tanta Scientific Nursing Journal}

AHRCCM Articles in Press, 2000;(24)13, 45-8.

25. Mohumed R. Role of the nurse in counseling parents of children with hereditary diseases, published thesis, Faculty of Nursing, Menoufiya University, 2005; 98.

26. Zahran S. Study of the organization and utilization of the neonatal intensive care unit in Tanta University Hospital, Unpublished Master Thesis in Faculty of Nursing, Alexandria University, 1991

27. Martensson I, Fridlund B. Patient's reports of health care practitioner interventions that are related to communication during mechanical ventilation, Heart\& Lung $\mathrm{J}$, 2004; 33(5): 308-20. 